\title{
Vegetable Grafting: History, Use, and Current Technology Status in North America
}

\author{
Chieri Kubota ${ }^{1}$ and Michael A. McClure \\ Department of Plant Sciences, The University of Arizona, 303 Forbes Building, \\ Tucson, AZ 85721-0036 \\ Nancy Kokalis-Burelle, Michael G. Bausher, and Erin N. Rosskopf \\ U.S. Horticultural Research Laboratory, U.S. Department of Agriculture, \\ Agriculture Research Service, Fort Pierce, FL 34945
}

Additional index words. automation, controlled environment, cucurbit, methyl bromide, root-knot nematode
rootstock, scion, Solanaceae

\begin{abstract}
Grafting of vegetable seedlings is a unique horticultural technology practiced for many years in East Asia to overcome issues associated with intensive cultivation using limited arable land. This technology was introduced to Europe and other countries in the late 20th century along with improved grafting methods suitable for commercial production of grafted vegetable seedlings. Later, grafting was introduced to North America from Europe and it is now attracting growing interest, both from greenhouse growers and organic producers. Grafting onto specific rootstocks generally provides resistance to soilborne diseases and nematodes and increases yield. Grafting is an effective technology for use in combination with more sustainable crop production practices, including reduced rates and overall use of soil fumigants in many other countries. Currently, over $\mathbf{4 0}$ million grafted tomato seedlings are estimated to be used annually in North American greenhouses, and several commercial trials have been conducted for promoting use of grafted melon seedlings in open fields. Nevertheless, there are issues identified that currently limit adoption of grafted seedlings in North America. One issue unique to North America is the large number of seedlings needed in a single shipment for large-scale, open-field production systems. Semi- or fully-automated grafting robots were invented by several agricultural machine industries in the 1990s, yet the available models are limited. The lack of flexibility of the existing robots also limits their wider use. Strategies to resolve these issues are discussed, including the use of a highly controlled environment to promote the standardized seedlings suitable for automation and better storage techniques. To use this technology widely in North American fresh vegetable production, more information and locally collected scientific and technical data are needed.
\end{abstract}

Grafting of herbaceous seedlings is a unique horticultural technology practiced for many years in East Asia to overcome issues associated with intensive cultivation using limited arable land for vegetable production. According to Lee and Oda (2003), a self-grafting technique to produce a large gourd fruit by increasing root-to-shoot ratio through multiple graftings was described in an ancient book written in China in the 5th century and in Korea in the 17th century. The first record of interspecific, herbaceous grafting as a yield increase and pest/disease control strategy was for watermelon [Citrullus lanatus (Thunb.) Matsum.\& Nakai], using a squash rootstock (Cucurbita moschata Duch.), reportedly developed by a watermelon farmer in Japan (Tateishi, 1927). This watermelon grafting technique was quickly disseminated to farmers through extension research programs of regional agricultural experimental stations in Japan, and then later into Korea, during the late 1920s and early 1930s. Use of grafted seedlings in commercial vegetable production occurred as early as the 1930s in Japan for watermelon grafted on Lagenaria siceraria (Mol.) Standl. (Oda, 2002). Research on grafting cucumber (Cucumis sativus L.) also started in the late 1920s, but wider commercial applications did not happen until 1960 (Sakata et al., 2008).

CEAC paper number D-302430-10-07.

We thank the USDA CSREES (Project \# 200751102-03822) for partial support.

${ }^{1}$ To whom reprint requests should be addressed; e-mail ckubota@ag.arizona.ed
For members of the Solanaceae, the first record was of eggplant (Solanum melongena L.) grafted on scarlet eggplant (Solanum integrifolium Poir.) in the 1950s (Oda, 1999). Grafting tomato (Lycopersicon esculentum Mill.) was introduced commercially in the 1960s (Lee and Oda, 2003). Along with the rapid development of intensive protected cultivation technologies using high tunnels and greenhouses, which presumably prevented farmers from continuing traditional crop rotation, vegetable grafting became a crucial tool to overcome soilborne diseases and other pests. In the 1990 s, nearly $60 \%$ of open fields and greenhouses in Japan producing muskmelon (Cucumis melo L.), watermelon, cucumber, tomato, and eggplant were reportedly planted with grafted seedlings (National Research Institute of Vegetables, Ornamental Plants and Tea, 2001) and 81\% in Korea (1990 data reported by Lee, 1994). Today, over 500 million grafted seedlings are produced annually in Japan (Kobayashi, 2005). One of the large-scale grafting operations in Japan is shown in Figure 1.

Although limited information is available, it seems that grafting of tomato was practiced at a limited scale in the United States more than 60 years ago. According to Lowman and Kelly (1946), grafting tomatoes using jimson weed (Datura stramonium L.) as rootstock was practiced for many years in the southern United States to overcome root-knot nematodes. Isbell (1944) recommended this method to home gardeners based on their research conducted from 1935 to 1943 on grafting tomato, eggplant, and sweet pepper on selected weeds. Nevertheless, grafting tomatoes to jimson weed was not introduced commercially, and apparently disappeared, presumably as a result of the potential transport of small amounts of alkaloids to the fruits, as experimentally proved by Lowman and Kelly (1946), and also because of the labor-intensive propagation process.

Intensive labor input and resulting high costs of grafted seedling production have been issues preventing this technology from being widely adopted outside of Asia. However, along with the development of efficient commercial production techniques for grafted seedlings and the introduction of new rootstocks with desirable traits compatible with locally selected scions, grafting technology was introduced to European countries in the early 1990s (Oda, 2002) mainly through marketing efforts of international seed companies and through information exchanges among research communities. The major objectives of using grafted seedlings are: 1) to achieve resistances to soilborne diseases and nematodes; 2 ) to increase yield and quality; and 3) to improve the physiology of plants making them more adaptable to harsh environments. Consequently, many countries in Europe, the Middle East, Northern Africa, Central America, and other parts of Asia (other than Japan and Korea) adopted the technology and the areas introducing grafted plants increased rapidly during the past two decades.

Until recently, grafted seedling production and its use were not common in North America. The exception was the home garden practice in the southern United States as described previously, and there have been 

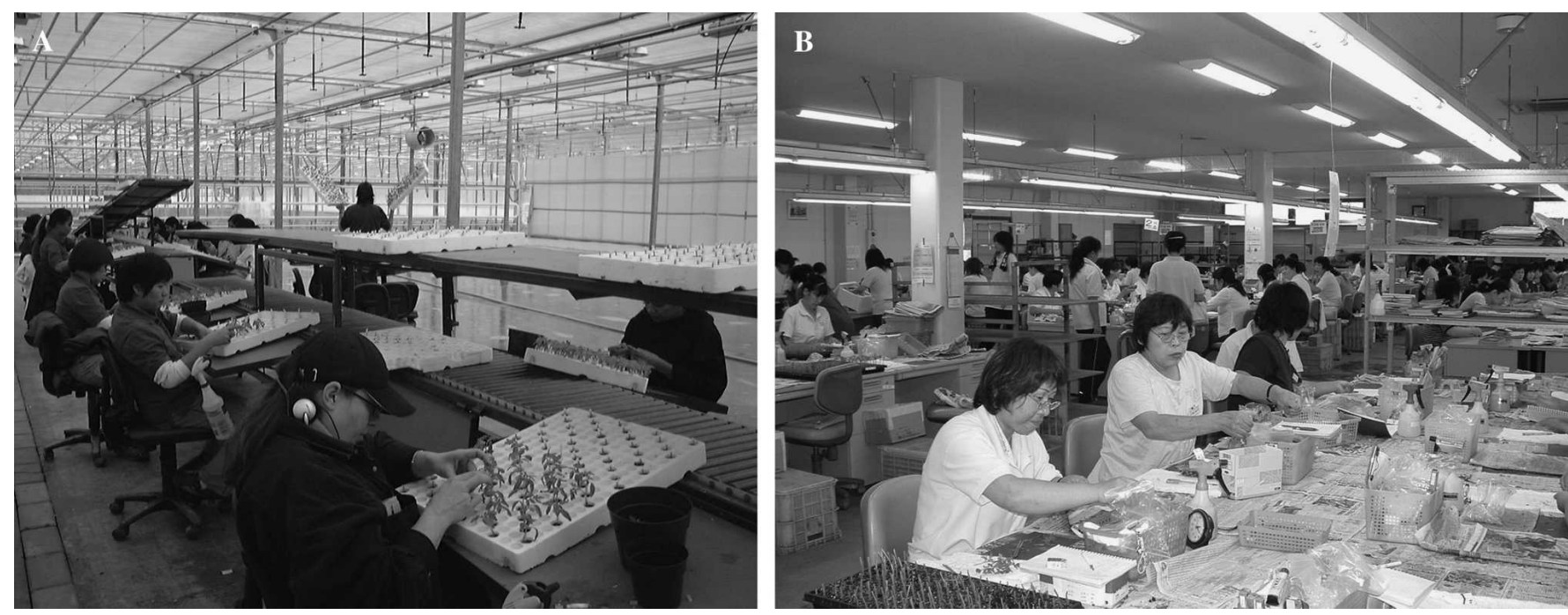

Fig. 1. Grafting operations in Canada (A) and in Japan (B). Each operation has the capacity to produce more than 10 million grafted seedlings annually.

small numbers of organic growers who practiced this technique by themselves to overcome soilborne diseases and pests in their small operations (M. Peet, personal communication). Recently, along with the success of European-based, large-scale greenhouse operations in North America, the improved yield and fruit quality by using grafted seedlings became known to more growers. The majority of users of grafted seedlings is currently greenhouse hydroponic tomato growers, whereas it is still a relatively unknown technique for open-field producers.

Recently, several trials in North America have been initiated using grafted seedlings for open-field vegetable production. Strong marketing efforts by seed companies and genuine interest from practitioners in integrated pest management have driven collaboration with producers, universities, and other research institutions. The authors currently work as an interdisciplinary team to develop necessary technologies, collect local information, and conduct trials in different climatic zones in the United States considering grafted plants as a means to mitigate yield losses to pathogens and to partially replace methyl bromide soil fumigation. In Mexico, Guatemala, and other countries, similar but larger-scaled projects led by the United Nations Industrial Development Organization contributed to disseminating information on the efficacy of vegetable grafting (UNIDO, 2007).

\section{CURRENT USE OF GRAFTED SEEDLINGS}

Although estimating the growing number of grafted plants used in North America is challenging, surveys conducted by faculty at the University of Arizona in 2002 and 2006 showed that the total number of grafted seedlings used in North America was over 40 million with the majority of these used in hydroponic tomato greenhouses. A relatively small number of grafted watermelon seed- lings were used for trials in open fields (less than 100,000 plants).

Many of the propagators supplying grafted seedlings to greenhouse growers are located in Ontario or British Columbia, Canada (Fig. 1). These propagators expanded their business successfully along with the success of greenhouse tomato growers. Because there are only small experimental propagation capabilities in the United States, large-scale propagators, each with $\approx 10$ million seedling production capacity in Canada, are still the major sources of the grafted seedlings used in the United States and northern Mexico. Many organic farmers and growers who produce in small greenhouse operations graft their own tomato seedlings because there are no local propagators available.

Grafted tomato seedling production and use. In most propagation operations in North America, grafting of tomato is accomplished by using an elastic plastic tube that holds the graft union cut at an angle (so-called "tube grafting method"). Each plastic tube has a slit so it falls off as the stem expands in diameter. Grafting speed using this tube grafting method varies from 300 to 500 grafts per hour depending on the worker's skill (J. Marie, personal communication). Grafting is usually performed $\approx 2$ to 3 weeks after seeding. Some rootstock seeds exhibit slower germination and require seeding 1 week earlier than the scion to develop compatible stem sizes at the time of grafting. Propagators need to optimize the seeding schedule for each selected combination of scion and rootstock so as to maximize the grafting success. Grafting young seedlings is considered advantageous as a result of the smaller size of seedlings, which allows greater seedling density and reduces the cost. After grafting, seedlings are placed under high humidity (greater than 95\%), ambient temperature $\left(27\right.$ to $\left.28^{\circ} \mathrm{C}\right)$, and low light intensity $(\approx 100$ $\mu \mathrm{mol} \cdot \mathrm{m}^{-2} \cdot \mathrm{s}^{-1}$ photosynthetic photon flux) for 4 to $7 \mathrm{~d}$ to heal the grafted union. Many North
American propagators use a humidification chamber or a simple covered structure inside a shaded greenhouse, whereas more sophisticated indoor healing units with better air temperature, relative humidity, and light intensity control capability are commercially available in other countries. This is probably because tomato grafting and healing methods are relatively easy and tomato is the major crop currently grafted in North America.

After healing, grafted tomato seedlings are acclimatized inside the greenhouse and then often pinched to induce two lateral shoots. This "two-headed" grafted seedling is widely accepted in greenhouse production systems where it reduces the production cost while maintaining the yield per head (and therefore overall yields) (Kubota, 2008; P. Rorabaugh, unpublished data).

Among the North and Central American countries, use of grafted tomato seedlings in open fields seems to be most advanced in Mexico. After 2 years of successful trials, tomato producers in Mexico have used grafted seedlings on 1250 acres (500 ha) to overcome Fusarium oxysporum f. sp. lycopersici race 3 , thereby attracting the interest of other producers (F. Knol, personal communication). Nevertheless, a recent outbreak of seedborne bacterial disease in a grafting trial in Mexico alerted propagators and producers to the seeds and seedlings from unreliable sources. Especially when the available sources of grafted seedlings and rootstock seeds are limited and, therefore, grafted seedlings travel a long distance, both propagators and producers must be cautious to prevent accidental introduction of diseases and viruses through transportation of seeds and seedlings.

Although there are many tomato rootstock varieties available worldwide, currently it seems that only one or two hybrid tomato rootstock varieties dominate the North American grafting rootstock market. This is probably the result of their early introduction and success in greenhouse 
tomato hydroponic production using the specific vigorous rootstocks. Making other alternative rootstocks available would help develop long-term strategies for pest and disease control, particularly for introduction of grafting into open-field tomato production.

Grafted cucurbit seedling production and use. Several commercial trials using grafted watermelon and muskmelon seedlings were conducted in multiple locations across the country to increase yield, quality, or to demonstrate grafting as a potential partial alternative to soil fumigants. Unlike members of the Solanaceae, in which tube grafting is the single dominant grafting method, cucurbit species are grafted using many different methods, including approach grafting, cotyledon grafting (a type of splice grafting), cleft grafting, and hole-insertion grafting (Lee and Oda, 2003). Some propagators use unrooted cuttings as rootstocks harvested before grafting, and root the grafted cuttings while the grafted unions are healed. These nonstandardized procedures for cucurbit grafting also make technology transfer challenging in cucurbits. Many North American propagators still rely on approach grafting, the slowest but most assured method for cucurbits.

\section{CURRENT AND FUTURE TECHNOLOGY NECESSARY TO WIDELY ADOPT GRAFTING IN NORTH AMERICA}

Wider use of grafted vegetable seedlings has considerable potential in North America. However, several issues described subsequently have been identified as major limitations.

Limitation of available rootstock information. Greenhouse tomato constitutes more than $90 \%$ of grafted seedling production in North America (Kubota, 2008). The majority of these seedlings are currently grafted to one or two common rootstocks. There is only limited information on the use of other rootstocks, compatibility to open-field cultivars, and field performance of grafted seedlings in various climatic conditions. Resistance information of rootstocks available from seed companies may not necessarily contain all the resistance/tolerance potentially exhibited in local soil and environmental conditions. One example is the recent finding that muskmelons grafted to interspecific hybrid squash (Cucurbita maxima $\times$ Cucurbita moschata) had resistance to vine decline caused by Monosporascus spp. (Cohen et al., 2000; Edelstein et al., 1999) and tolerance to charcoal rot (Macrophomina phaselina) (C. Kubota et al., unpublished data).

Other rootstock information missing but critical in applications to North America is efficacy over root-knot nematode (RKN) (Meloidogyne spp.). Many tomato rootstocks contain the $M i$ gene and have been incorporated into many tomato cultivars for resistance to RKN as demonstrated using 'Beaufort' rootstock by Cao et al. (2005). A drawback of the $M i$ gene, however, is its sensitivity to temperature, and failure of resistance can occur at high soil temperature (Dropkin, 1969; Williamson, 1998). Nematode isolates capable of breaking $M i$ resistance have also been identified in many areas of world (Williamson, 1998). Ioannou (2001) examined a tomato rootstock for grafting eggplant and found reduced efficacy of grafting against RKN in summer crops, presumably as a result of the high soil temperature. More information is needed on the effectiveness of various tomato rootstocks under high soil temperatures (critical temperatures are generally above $28^{\circ} \mathrm{C}$ ) (Dropkin, 1969). Wildtype-based tomato rootstocks may have other resistance genes that are stable at higher soil temperatures. Such high temperature-resistant genes were reportedly found in Lycopersicon spp. (Williamson, 1998). Therefore, resistance screening tests need to be conducted at varied temperatures using RKN species specific to the location in which grafted plants are to be introduced. Such information is particularly critical for applying grafting technology in Mexico and the southern United States, including Florida and south Texas, to identify overall resistance of rootstocks to multiple pests and diseases under subtropical conditions.

To our knowledge, cucurbit rootstocks with $\mathrm{RKN}$ resistance are not commercially available, but there are a few species that are promising candidates. Igarashi et al. (1987) examined several wild Cucumis species, including Kiwano (Cucumis metuliferus Naud.), for resistance to RKN and grafting compatibility to muskmelon. Considering all aspects, including fruit size and yield, Igarashi et al. (1987) concluded that C. metuliferus is the most suitable rootstock exhibiting good resistance to RKN. Recently, a research group in California (Sigüenza et al., 2005) reported that $C$. metuliferus can be used as a rootstock for muskmelon to prevent both plant growth reduction and nematode population increases in $M$. incognita-infested soil. Sigüenza et al. (2005) also found that C. moschata rootstock, a traditional rootstock used for cucurbits in Asia, had a high level of tolerance to $M$. incognita.

Information on resistance/tolerance of commercially available rootstocks and potential germplasm usable for breeding new rootstocks needs to be collected based on locally conducted trials and research. Germplasms that are considered as weeds elsewhere are sometimes introduced as new rootstocks. For example, selected lines of Solanum torvum Swartz (Turkey berry, a weed widespread in Florida) from germplasm collected from Puerto Rico and Thailand have been used for grafting solanaceous plants in Japan (Takii Seeds, personal communication). The vigorous growth characteristics of $S$. torvum in various ecosystems is an attractive feature to introduce for Solanaceae rootstocks. Introduction of biotechnology to rootstock development has been also attempted by researchers (e.g., Gal-On et al., 2005).
Limitations of propagators experience with grafting. The majority of propagators capable of grafted vegetable seedling production are located in Canada and Mexico. Currently, U.S. propagators have limited experience. Furthermore, a limited number of university extension and research institutions are familiar with the specific techniques of grafted seedling production. Consequently, many propagators in North America had to learn grafting technologies from practitioners in countries such as Korea, Spain, The Netherlands, and Israel.

Limited access to information on the process of grafting seedlings and production scheduling only available in languages other than English is an additional issue. A shortage of well-trained propagators with experience in grafted seedling production also limits wider application in North America. Education and dissemination of information through workshops and short courses is important but will reach only a limited number of stakeholders. The authors are in the process of developing an informational web site to reach a wider audience and a larger number of stakeholders.

Handling large numbers of grafted seedlings. Another issue unique to North America is the large number of seedlings needed in a single shipment. The labor available within a propagation operation will limit the number of plants available for delivery at a given time. One solution is the development of short-term seedling storage techniques, which can distribute available labor input for grafting over time while targeting a narrow shipping window. Tomato and eggplant seedlings can be stored at low temperatures under dim light for up to 4 to 6 weeks (Kubota, 2003), but storage protocols are not well developed for cucurbits. Lowering temperature can slow the respiration and metabolic processes and thereby prevent undesirable quality degradation. In postharvest storage, temperature is generally selected to be the lowest possible temperature that does not cause chilling injury (CI) to the produce. For storage of seedlings, avoiding $\mathrm{CI}$ and maintaining photosynthetic and regrowth abilities are necessary. Both temperature and light environments are important to optimize storability of seedlings (Heins et al., 1992; Kubota, 2003). Grafting on chilling-tolerant rootstocks may extend the storability of the seedlings and therefore information should be collected for different graft combinations.

The introduction of mechanization and automation technology will also help address large-scale production issues. Efficient labor management has been recognized as a key to success in mass production of grafted seedlings. Semi- or fully-automated grafting robots were invented by several agricultural machine industries (Kurata, 1994) and some models are available in East Asia, Europe, and more recently in the United States. According to Kobayashi (2005), the first commercial model of a grafting robot (GR800 series; Iseki \& Co. Ltd., Matsuyama, 
Japan) became available for cucurbits in 1993 and there were various semi- and fully automated grafting robots presented from nine different agricultural machine industries at an international horticultural trade show in Tokyo in 1996. Kobayashi (2005) also noted that grafting robots were developed in other countries, and a semiautomated system suitable for multiple species, including cucurbits, members of the Solanaceae, and roses, became available from Arnabat S.A. (Barcelona, Spain) in 2000. Another semiautomated grafting robot for cucurbits, similar to Iseki's GR800, was developed in Korea in 2004 (GR-600; Helper Robotech Co., Gimhae, Korea). For fully automated grafting robots, in 1994, Yanmar Agricultural Equipment Co. (Osaka, Japan) introduced an AG1000 robot for grafting solanaceous plants based on a 128-cell tray system, in which an entire row of eight seedlings could be grafting at one time, achieving a speed of 1200 grafts per hour with one assisting operator. Unfortunately, many of these grafting robots introduced to commercial propagators in the late 1990 s and the early 2000 s are underused in operations. Kobayashi (2005) pointed out several issues, including challenges in producing scion and rootstock seedlings that consistently meet the size and quality specifications required by grafting robots. Along with internationalization of grafting technology and emerging demand from counties like the United States where labor management is a significant issue in agriculture and horticultural operations, improving grafting robots and seedling production technology adoptable to automation is an immediate need. Several groups of researchers and engineers in Japan currently work on improvement of the relatively old grafting robot technology or on development of more flexible grafting robots. One such effort is a fully automated grafting robot for cucurbits, which was recently developed based on the 1993 version of Iseki's GR800 semiautomated robot (K. Kobayashi and K. Shigematsu, personal communication). The prototype model (Fig. 2) has scion and rootstock feeders, which pick, orient, and feed the scion and the rootstock shoots to the grafting processor, performing 750 grafts per hour with a $90 \%$ success rate. The new robot will be commercially available in a few years.

High production costs. Our recent survey found that the price of tomato seedlings for fresh market tomato production is currently $\$ 0.03$ to $\$ 0.40$ per seedling (excluding seed costs), whereas the current price of grafted melon and tomato seedlings is $\$ 0.60$ to $\$ 0.90$ in addition to seed costs. The high cost of grafted seedlings is the result of intensive labor input for propagation, a longer production period, and the additional costs of the rootstock. Those expenses often discourage potential users of grafted seedlings. Not often acknowledged is that growers may be compensated for the greater initial cost of buying grafted seedlings by additional benefits of increased yield and reduced cost of control measures for soilborne pests. According to

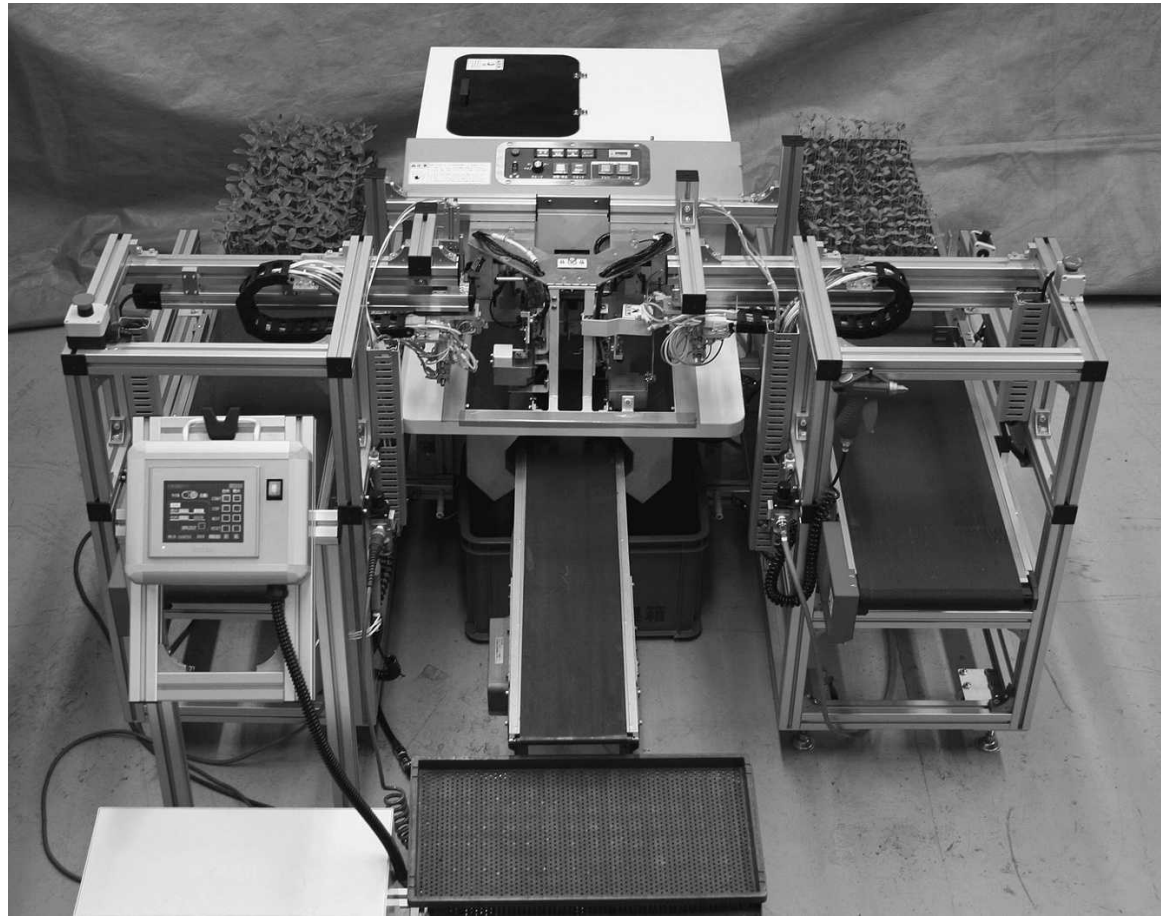

Fig. 2. A prototype of a fully automated grafting robot for cucurbits with a capability of 750 grafts per hour (courtesy of BRAIN, Saitama, Japan).

the EPA (1997), fumigation with methyl bromide costs $\$ 0.41$ to $\$ 0.92$ per plant, almost comparable to the current cost for buying a young grafted seedling produced in Canada ( $\$ 0.90$ per a "double-headed" plant or $\$ 0.45$ per head), although the cost of the grafted plant does not account for other pest control tactics such as effective herbicide packages required in the absence of methyl bromide. Further investigation and economic analyses are necessary taking local economic, agronomic, and pathologic situations into consideration. The University of Arizona also conducted a yield comparison in tomato and found an increase of $\approx 15 \%$ when grafted plants were compared with nongrafted seedlings in both a greenhouse (P. Rorabaugh, unpublished data) and in a small field trial with low disease pressure (C. Kubota, unpublished data). It may be possible to pair grafting with effective, site-specific herbicide packages to accomplish production with yields similar to those achieved in open-field production using soil fumigation, which would give growers an incentive to use grafted seedlings.

Long-distance transportation. As a result of the limited availability of grafted seedlings, greenhouse tomato growers often purchase grafted seedlings from distant propagators, risking deterioration of transplants during transportation and the consequential delayed growth or fruit development (Kubota and Kroggel, 2006). It has been observed that lower temperatures and illumination significantly maintained transportability of the seedlings. For mature tomato seedlings at flowering stage, simulated transport at 6 to $13{ }^{\circ} \mathrm{C}$ showed the best transport- ability without experiencing negative impact for the 4-d simulated transportation. Seedlings at $18{ }^{\circ} \mathrm{C}$ exhibited serious quality deterioration, delay in early season growth and development, loss of flower buds on the first truss, and yield reduction (Kubota and Kroggel, 2006). Transportation conditions need to be modified according to plant growth stage and plant quality at the time of transportation. Air freight is an alternative transportation means for smaller seedlings and plugs but has less flexibility in controlling temperature than refrigerated trucks. Trailers temperature can be selected to prevent $\mathrm{CI}$ while minimizing the physiological deterioration of plants resulting from excessive respiration and ethylene accumulation during transportation. The vapor pressure inside trailers is generally very close to saturation $(100 \%$ relative humidity) as a result of the floor-to-ceiling loading of seedlings. This high humidity sometimes causes rapid spread of disease. Damage to grafted seedlings resulting from an unpredicted event such as an unanticipated prolonged duration of transportation or disease epidemic could result in a long-term impact on plant growth and yield.

New controlled environment technology. One critical item necessary for successful grafted seedling production is uniformity of seedlings used for scion and rootstock. One way to improve the uniformity is the use of automatic sorting machines equipped with a machine vision system as successfully used in Europe and Canada. Another approach is the use of production systems under artificial lighting. The latter can contribute to the ability to manipulate production scheduling. 


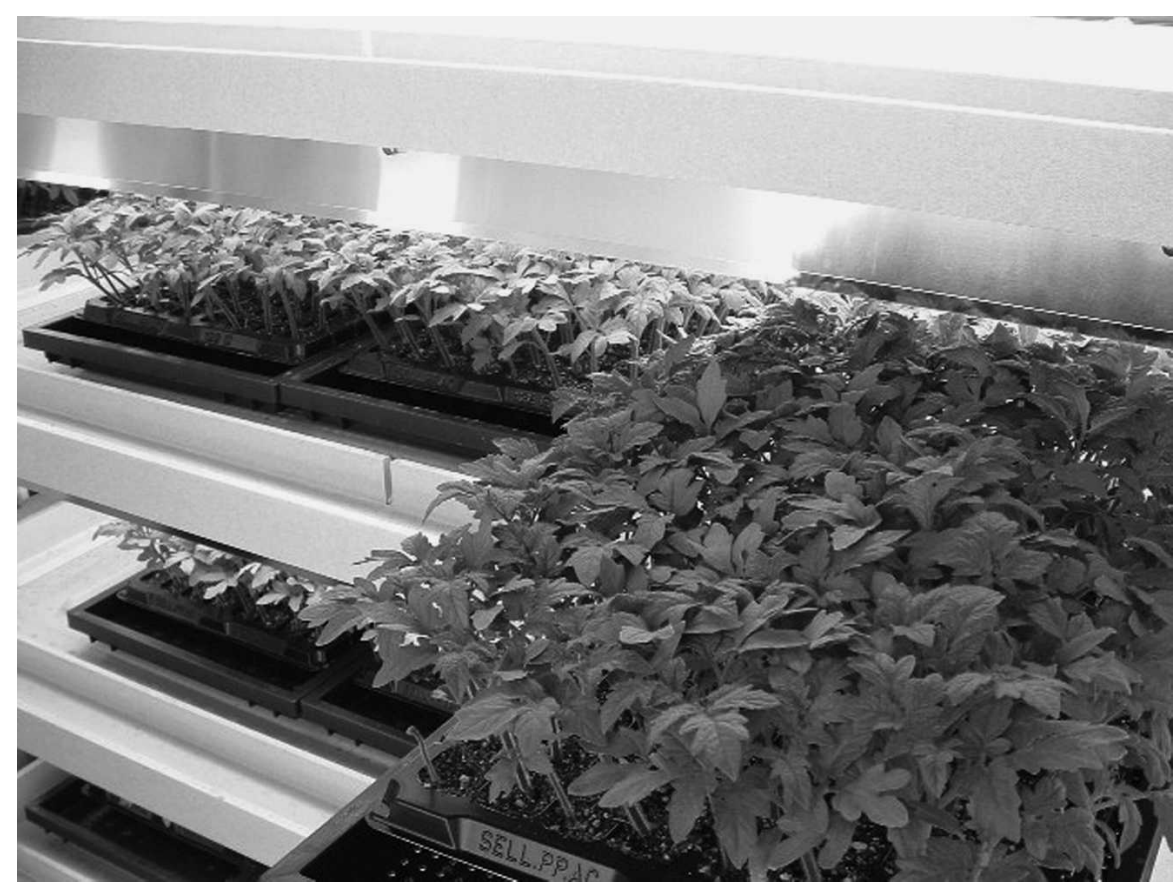

Fig. 3. High-quality seedlings with uniform size suitable for grafting produced under artificial lighting (white fluorescent lamps) inside a closed system. The technology has been adopted by commercial propagators in Japan.

As a result of the relatively short duration of each growth stage of grafted seedling production, fluctuations in weather can often change the entire production schedule, and shipping schedules must be adjusted accordingly. As a result of a short production cycle and the consistent seedling quality, use of artificial environments to produce grafted seedling plugs can be feasible, especially for mass production systems. The advantages of using an artificial environment are the predictable production schedule and standardized seedling quality as a result of the consistent environmental conditions and therefore plant growth and development. Production of scion and rootstock seedlings having a standardized quality will facilitate use of automation in the grafting process. Failure resulting from lack of uniformity among plants is a common cause of ineffective use of grafting robots (Kobayashi, 2005).

Techniques for producing transplants under artificial lighting have been recently adapted to commercial propagators after the successful development of a commercially available transplant production unit in Japan (Tsuchiya, 2003) (Fig. 3). Research directed toward transplant production using artificial lighting systems under controlled environments was initiated in the late 1980s. Dreesen and Langhans $(1991,1992)$ reported that using such systems was profitable because of a high value per unit of production area and a short production time of transplants. Ohyama et al. (2003) reported that the cost of electricity for growing tomato seedlings for $17 \mathrm{~d}$ under artificial lighting in a closed production system with good insulation and containment will be $116 \mathrm{kWh}$ per each square meter of production area (equivalent to 2.9 to
3.2 Japanese Yen or $\$ 0.03$ per seedling grown in a 128-cell tray). Today, advanced Japanese commercial propagators successfully use closed-type production systems with artificial lighting for growing uniform scion and rootstock seedlings, a critical stage in grafted seedling production. Closed-type seedling production systems and automatic grafting machines should be adopted in North American grafted seedling production to process a large number of grafted plants with limited labor. Closed-type seedling production system also has a significant advantage over conventional greenhouse propagation if one considers the quarantine and certification demands of importation for out-of-state or international production of grafted seedlings.

\section{Conclusions}

Herbaceous grafting has been practiced for many years in countries in Asia, Europe, the Middle East, Northern Africa, and Central America, and now it has been introduced as a relatively new technology in North America. As a result of its benefits and value, demand for high-quality grafted seedlings by growers and interest by propagators are expected to rapidly increase. Researchers, extension specialists, and industries need to work together to integrate this modernized technology as an effective tool for sustainable horticultural production in North America.

\section{Literature Cited}

Cao, Z.P., G.K. Chen, Y.F. Chen, H. Yang, L.F. Han, and R. Dawson. 2005. Comparative performance of nematode resistant rootstock and non-resistant tomato cultivars on soil biota. Allelopathy Journal 15:85-94.

Cohen, R., S. Pivonia, Y. Berger, M. Edelstein, A. Gamliel, and J. Katan. 2000. Toward integrated management of Monosporascus wilt of melons in Israel. Plant Dis. 84:496-505.

Dreesen, D.R. and R.W. Langhans. 1991. Uniformity of impatiens plug seedling growth in controlled environments. J. Amer. Soc. Hort. Sci. 116:786-791

Dreesen, D.R. and R.W. Langhans. 1992. Temperature effects on growth of impatiens plug seedlings in controlled environments. J. Amer. Soc. Hort. Sci. 117:209-215.

Dropkin, V.H. 1969. The necrotic reaction of tomatoes and other hosts resistant to Meloidogyne: Reversal by temperature. Phytopathology 59:1632-1637.

Edelstein, M., R. Cohen, Y. Burger, S. Shriber, S. Pivonia, and D. Shtienberg. 1999. Integrated management of sudden wilt in melons, caused by Monosporascus cannonbolus, using grafting and reduced rates of methyl bromide. Plant Dis. 83:1142-1145.

EPA. 1997. Methyl bromide alternative case studies. Vol. 3. 18 Sept. 2007. <http://www.epa. gov/spdpublc/mbr/casestudies/volume3/index. html>.

Gal-On, A., D. Wolf, Y. Antignus, L. Patlis, K.H. Ryu, B.E. Min, M. Pearlsman, O. Lachman, V. Gaba, Y.Z. Wang, Y.M. Shiboleth, J. Yang, and A. Zelcer. 2005. Transgenic cucumbers harboring the 54-kDa putative gene of Cucumber fruit mottle mosaic tobamovirus are highly resistant to viral infection and protect nontransgenic scions from soil infection. Transgenic Res. 14:81-93.

Heins, R.D., N. Lange, and T.F. Wallace, Jr. 1992. Low temperature storage of beddingplant plugs, p. 45-64. In: Kurata K. and K. Kozai (eds.). Transplant production systems. Kluwer Academic, Dordrecht, The Netherlands.

Igarashi, I., T. Kano, and T. Kawabe. 1987. Disease and pest resistance of wild Cucumis species and their compatibility as rootstock for melon, cucumber and watermelon. Bull. Natl. Res. Inst. Veg. Ornam. Plants and Tea Japan. A1: $173-185$.

Ioannou, N. 2001. Integrating soil solarization with grafting on resistant rootstocks for management of soil-borne pathogens of eggplant. J. Hort. Sci. Biotech. 76:396-401.

Isbell, C.L. 1944. Pass the word to gardeners: Graft tomatoes onto weeds. Southern Seedsman, April:14, 42.

Kobayashi, K. 2005. Vegetable grafting robot Research Journal of Food and Agriculture 28:15-20

Kubota, C. 2003. Environmental control for growth suppression and quality preservation of transplants. Environ. Control. Biol. 41:97105.

Kubota, C. 2008. Use of grafted seedlings for vegetable production in North America. Acta Hort. (in press).

Kubota, C. and M. Kroggel. 2006. Air temperature and illumination during transportation affect quality of mature tomato seedlings. HortScience 41:1640-1644.

Kurata, K. 1994. Cultivation of grafted vegetables. 2. Development of grafting robots in Japan. HortScience 29:240-244.

Lee, J.-M. 1994. Cultivation of grafted vegetables. 1. Current status, grafting methods, and benefits. HortScience 29:235-239.

Lee, J.-M. and M. Oda. 2003. Grafting of herbaceous vegetable and ornamental crops, p. 61-124. In: 
Janick J. (ed.). Horticultural reviews. Vol. 28. John Wiley \& Sons, New York, NY.

Lowman, M.S. and J.W. Kelly. 1946. The presence of mydriatic alkaloids in tomato fruit from scions grown on Datura stramonium rootstock. J. Amer. Soc. Hort. Sci. 48:249-259.

National Research Institute of Vegetables, Ornamental Plants and Tea. 2001. Current use and issues in grafted vegetable seedling production. Report No. 9, National Research Institute of Vegetables, Ornamental Plants and Tea, Japanese Ministry of Agriculture, Forestry and Fisheries.

Oda, M. 1999. Grafting of vegetables to improve greenhouse production. Food \& Fertilizer Technology Center Extension Bulletin 480:1-11.
Oda, M. 2002. Grafting of vegetable crops. Sci. Rep. Agr. \& Biol. Sci. Osaka Pref. Univ. 54:49-72.

Ohyama, K., K. Manabe, Y. Omura, C. Kubota, and T. Kozai. 2003. A comparison between closed-type and open-type transplant production systems with respect to quality of tomato plug transplants and resource consumption during summer. Environ. Control in Biol. 41:57-61.

Sakata, Y., T. Ohara, and M. Sugiyama. 2008. The history of melon and cucumber grafting in Japan. Acta Hort. 767:217-228.

Sigüenza, C., M. Schochow, T. Turini, and A. Ploeg. 2005. Use of Cucumis metuliferus as a rootstock for melon to manage Meloidogyne incognita. J. Nematol. 37:276-280.

Tateishi, K. 1927. Grafting watermelon on squash. Japan. J. Hort. 39:5-8.

Tsuchiya, K. 2003. Transplant production system with artificial lighting, p. 373-375. In: Handbook for protected cultivation. 5th Ed. Japan Greenhouse Horticulture Association, Tokyo, Japan.

UNIDO. 2007. Methyl bromide phaseout projects. United Nations Industrial Development Organization. 18 Sept. 2007. <http://www.unido. org/doc/29643\#Projects>.

Williamson, V.M. 1998. Root-knot nematode resistance genes in tomato and their potential for future use. Annu. Rev. Phytopathol. 36:277293. 